\title{
Metal Induced Crystallization
}

\author{
Ahamad Mohiddon Mahamad and Ghanashyam Krishna Mamidipudi \\ School of Physics, University of Hyderabad, Hyderabad, \\ India
}

\section{Introduction}

Polycrystalline silicon thin films have attracted the attention of semiconductor industries in the past few decades due to their wide applications in thin film transistors, solar cells, display units and sensors (Schropp \& Zeman, 1998; Choi et al., 2005; Mahan et al., 2008). Polycrystalline Si thin films are generally fabricated by crystallizing amorphous $\mathrm{Si}(\mathrm{a}-\mathrm{Si}$ ) thin films, because these can render larger grains compared to the conventional poly Si film deposition. As a consequence, a variety of methods for lowering the crystallization temperature of a-Si have been developed. Excimer laser annealing is one of the promising ways to achieve large grain size poly Si films at lower substrate temperatures. Its high costs and nonuniform grain size, however, are significant obstacles that prevent its wide use (Parr et al., 2002). The other promising technique is the solid phase crystallization method. But this technique is essentially a high-temperature process and many substrates, including most forms of glass, cannot withstand the thermal processing. In order to achieve lower costs and have a wider range of application, inexpensive materials such as glass and special polymers have to substitute quartz or Pyrex ${ }^{\mathrm{TM}}$ substrates. In the case of glass substrates, all of the processing steps need to be limited to temperatures below $550{ }^{\circ} \mathrm{C}$. The other known technique is rapid thermal annealing (RTA). In RTA infrared radiation is used as a heating source, and has the advantage of the high heating speed (up to $60^{\circ} \mathrm{C} / \mathrm{s}$ ) that reduces the crystallization time. In RTA radiation is applied in pulses to heat the sample without heating the glass substrate (which is transparent to the infrared radiation). However, the grain size obtained in the crystallization of a-Si is also in the range of a few micrometers.

In an effort to reduce the crystallization temperature and crystallization time, and to increase the grain size, metal-induced crystallization (MIC) has been investigated as an alternative crystallization process for thin-film device fabrication. The MIC process involves the deposition of a-Si films on top of which a layer of suitable metal is deposited. This bilayer of metal and $\mathrm{Si}$ is then annealed in a furnace at temperatures ranging from 150 to 700 ${ }^{\circ} \mathrm{C}$ for durations between one minute to several hours leading to crystallization of the a-Si. As a result the $\mathrm{Si}$ nanocrystals grow in the metal/metal silicide/metal oxide matrix and their growth rate depends on the annealing conditions of the bilayer. Thus, to grow the Si nanocrystals, both thermodynamics and kinetics of the process have to be understood in detail. In the MIC process, metals like aluminum, nickel, gold, silver etc are used to decrease the crystallization temperature below $700{ }^{\circ} \mathrm{C}$. Among the metals employed for the study of the MIC (Jin et al.,1999; Kumar et al.,2007; Kumar et al.,2008; Mohiddon \& Krishna, 2011), the preferred metal up to date has been nickel $(\mathrm{Ni})$ due to its low residual metal 
contamination in the poly-Si region (Wang \& Wong, 2001). The mobility and the transfer characteristics of the poly Si TFT are improved by reducing the leakage current caused by the metal agents. To achieve this, metal-induced lateral crystallization (MILC) has been introduced. Ni induced MILC TFTs' are now widely used in large display applications. Large number of metals have been investigated to crystallize the a-Si at possible low temperature. These metals are classified in to two groups basing on the mechanism they follow in crystallizing the a-Si matrix. One group of metals forms eutectic with a-Si (follows Layer exchange mechanism) and the other reacts with a-Si and forms silicide. The eutectic phase forming metals can produce extended continuous poly-Si films with large grain size of $10 \mu \mathrm{m}$ (Oliver \& Hartmann, 2000). However, these metals contaminate the so produced $c$-Si and degrade its properties. Thus, the search for metals that would lead to crystallization of $a$-Si thin film at low temperatures and also reduce the contamination is a subject of recent research.

The aim of this review is to present an overview of the current state of understanding of the mechanisms involved in MIC and to discuss some of the recent work of the current authors in this area. The motivation is to crystallize a-Si films using metals that have not been investigated in detail so far, in addition to $\mathrm{Ni}$ which is a well studied metal used in the MIC process. The two other metals that were selected for this study are Tin (Sn) and Chromium $(\mathrm{Cr})$. The former is known to form a eutectic alloy with the $\mathrm{Si}$ whereas the latter is a silicide/oxide forming metal, similar to Nickel. Furthermore, results on two different types of geometries are presented; the first involves the deposition of metal on top of the a-Si film, while in the second geometry the a-Si film is deposited on top of the metal film. This provides very interesting insights in to the mechanisms that cause crystallization of a-Si.

\section{Mechanisms of metal induced crystallization}

The main mechanisms of metal induced crystallization are discussed in this section.

\subsection{Layer exchange mechanism}

The proposed formation of poly-Si films on foreign substrates by eutectic forming metals relies on the overall layer exchange of adjacent $\mathrm{Si}$ and metal films during the transformation of amorphous to polycrystalline $\mathrm{Si}$. The phenomenon is named as "layer exchange mechanism". The general driving force behind metal-induced crystallization is the reduction of the free energy of the silicon material during the transformation of the amorphous to the crystalline phase. When $a$-Si is in contact with certain metals, electronic screening of the covalent bonding in the Si material occurs, which weakens the Si bonds, and therefore, facilitates the inter diffusion of the metal and silicon atoms (Hiraki, 1980). The representatives of the eutectic forming metals are $\mathrm{Au}, \mathrm{Ag}$ and Al. Aluminum-induced crystallization [AIC] is extensively studied metal to form extended continuous poly-Si films of large-grained material on glass, which is desirable for thin film solar cells.

The AIC comprises the diffusion of Si atoms into the Al layer, which occurs due to the fact that adjacent $\mathrm{Al}$ and $\mathrm{Si}$ layers are not in thermal equilibrium at elevated temperatures. According to the $\mathrm{Al} / \mathrm{Si}$ phase diagram, up to 1.5 at.\% of $\mathrm{Si}$ can be dissolved in $\mathrm{Al}$ at temperatures below the eutectic temperature of $577{ }^{\circ} \mathrm{C}$ (Murray \& McAlister, 1984). The initial interaction of the $\mathrm{Al}$ and $a$-Si layers involves the partial dissolution of the $\mathrm{Al}$ or $\mathrm{Si}$ 
oxide interface layer, depending on the layer sequence, to allow the inter diffusion of the materials. The Si oxide layer is transformed by the $\mathrm{Al}$ into a mixture of $\mathrm{Al}$ oxide and an $\mathrm{Al}_{x} \mathrm{Si}$ phase. This newly formed $\mathrm{Al}_{x} \mathrm{Si}$ phase provides a diffusion channel for the $\mathrm{Si}$ and $\mathrm{Al}$ atoms (Nast \& Wenham, 2000). The evaporated Al films are of polycrystalline nature, there are four different diffusion paths available for the diffusion of the Si atoms. 1) Diffusion inside the $\mathrm{Al}$ grains, 2) Diffusion along $\mathrm{Al}$ grain boundaries, 3) Diffusion along the $\mathrm{Al} / \mathrm{a}-\mathrm{Si}$ interfaces, and 4) Diffusion along the glass/ $\mathrm{Al}$ interface.

The diffused $\mathrm{Si}$ atoms start crystallizing near the $\mathrm{Al} / a$-Si interface. The $\mathrm{Al}$ grain boundaries are preferential nucleation sites for the dissolved $\mathrm{Si}$ atoms, since they are the sites of low critical free energy for nucleus formation. According to the random successive nucleation model, at early stage of crystallization, Si nuclei are formed at preferred sites located at the $\mathrm{Al} / \mathrm{Si}$ interface. The released heat (crystallization energy and strain energy) leads to rise the local temperature in ambient regions. The temperature field propagates fast, since the thermal diffusion is faster than the atomic diffusion, so that the heat flow can stimulate new nuclei appearing randomly in nearby region. These nuclei of the next generation also produce a local temperature rise. This process repeats many time during annealing, resulting in a fractal formation.

Silicon atoms, dissolved in the Al layer, have a high mobility and, hence, diffuse quickly within the film and/or along the interfaces towards the growing Si grains (McCaldin \& Sankur, 1971). It is this fast growth within the Al layer compared to any other growth normal to the layer structure that leads to the formation of a continuous poly-Si film. At an early stage of the crystallization process the newly formed Si grains within the Al matrix are far apart and do not influence each other. The nucleation rate strongly depends on the defects and grain boundaries in the Al layer as well as the temperature and corresponding silicon concentration. Si solute depletion occurs up to the effective diffusion distance in the vicinity of the growing grain (Zener, 1949). In this region the possibility of new nucleation decreases with increasing depletion towards the advancing $\mathrm{Al} / \mathrm{Si}$ grain interface. When the effective diffusion distances of adjacent grains begin to overlap, competition for the available Si atoms dissolved in the Al layer occurs. At this point, the possibility of new nuclei formation decreases. This type of crystallization pattern, where isolated grains start to interfere at an early stage of the process, is different to solid-phase crystallization of amorphous silicon (Spinella et al., 1998).

The grain-size distribution is dependent on the ratio of the grain growth to the nucleation rate. This ratio increases with decreasing annealing temperature (Nast \& Wenham, 2000). The decrease in grain growth due to a lower annealing temperature is less than the decrease in nucleation rate. The effective diffusion distance is longer at lower annealing temperatures leading to larger depletion areas around the growing grains, which prevents further nucleation. Therefore, the grains grow to a larger size before impingement occurs. The nucleations as well as the diffusion-controlled growth are thermally activated processes. Once the size of the Si grains is equivalent to the thickness of the Al layer, they solely advance laterally since they are constrained by the substrate and the $a$-Si/Al interface. Throughout the poly-Si growth process the Al layer is gradually displaced. The continuous supply of $\mathrm{Si}$ atoms from a-Si layer and gradual displacement of $\mathrm{Al}$ atoms leads to the growth of poly Si film with the large grain size. As an alternative member of this group of metals, we have investigated the tin induced a-Si crystallization. 


\subsection{Mechanism of diffusion assisted crystallization}

Two main mechanisms of diffusion assisted crystallization are proposed in literature. One is based on the diffusion and movement of $\mathrm{Ni}$ in the $a$-Si matrix causing crystallization of $\mathrm{Si}$ around dispersed nanostructured $\mathrm{NiSi}_{2}$ seeds (Ni diffusion assisted MIC); the other is based on the formation of the silicides at the interface between $\mathrm{Ni}$ and $\mathrm{Si}$ layers, which then moves into the $a$-Si matrix, leading to crystallization of Si (MILC)

According to the first mechanism, the metal (Ni) at first diffuses through $a$ - Si matrix and then forms $\mathrm{NiSi}_{2}$ at a sufficient high temperature. This silicide will then act as seed for the crystallization of $a$-Si. The concept of metal diffusion is proposed on the basis of the experimental observations reported in the literature. Park et al. [Park et al., 2001] reported secondary ion mass spectroscopy (SIMS) and transmission electron microscope studies on excimer laser annealed Ni induced crystallization of poly Si. They measured the melting temperatures as a function of $\mathrm{Ni}$ content and reported that $a-\mathrm{Si}$, just below the Ni layer, melted at lower temperature and the melting point increases with movement away from the $\mathrm{Ni}$ rich layer. The change in melting point was attributed to change in Ni concentration. Their explanation for the observed behaviour was that, the Ni diffuses through $a$-Si matrix only when a sufficiently high temperature is reached. Ferri et al. [Ferri et al., 2001] studied diluted metal contaminated $a$-Si system by detailed Raman spectroscopy measurement and came to similar conclusions.

The knowledge of formation, structure and electrical behaviour of a metal-semiconductor interfaces plays an important role in semiconductor technology. The nickel monosilicide (NiSi) is a low resistance silicide in Ni-Si binary system, and is a key material to reduce the contact resistance of gate and source-drain regions. I. H. Hong et al. (Hong et al., 2006) carried out scanning photoelectron spectromicroscopy on the a-Si/Ni films, which were deposited by chemical vapor deposition at ultra high vacuum pressure. They state that when the $\mathrm{Si} / \mathrm{Ni}$ interface is heated, $\mathrm{Ni}_{2} \mathrm{Si}$, which is an unstable phase with high resistivity, is first formed at $200-300{ }^{\circ} \mathrm{C}$. At around $300{ }^{\circ} \mathrm{C}$ or above, $\mathrm{Ni}_{2} \mathrm{Si}$ starts transformation into a low resistivity phase $\mathrm{NiSi}$. The $\mathrm{Ni}_{2} \mathrm{Si}$ phase disappears at above $400^{\circ} \mathrm{C}$. Another high resistivity phase, $\mathrm{NiSi}_{2}$, nucleates at above $750{ }^{\circ} \mathrm{C}$. Another method of enhancing metal diffusion is electric field assisted MIC (FAMIC). In FAMIC, the crystallization of a-Si is enhanced by applying an electric field to the metal/Si binary system.

The two major driving forces for the MIC process are (1) the free-energy gradient between silicon and metal silicides, (2) the concentration gradient caused by atomic diffusion in metal/silicon stacked films. In addition to these driving forces, the applied electrical field introduces an additional driving force to lower the activation energy for crystallization. Lee (Lee et al., 2000) suggested in the study of a Cu/Si FAMIC system that the electrons can charge up at the a-Si surface of the $\mathrm{Cu}$ silicide/a-Si interface under an applied voltage. The $\mathrm{Cu}$ ions with positive charges could then migrate at a faster speed, resulting in a directional and rapid lateral movement of $\mathrm{Cu}$ silicide/a-Si interface and so the crystallized poly-Si can be formed at the enhanced speed. The similar enhanced growth rate is reported in $\mathrm{Ni} / \mathrm{Si}$ system. It has been postulated that the enhanced growth rate is a result of field-enhanced diffusion of nickel atoms (Park et al., 1999; Yoon et al., 2001). Having an effective charge of $0.3299 \mathrm{e}$ in the $\mathrm{Si}$ lattice, $\mathrm{Ni}$ atoms move toward the positive electrode under an electric field 
(Yoon et al., 2001). The other mechanism of FAMIC considers the bombardment of Ni atoms by electrons traveling in an $a$-Si layer. Nickel atoms are pushed toward the positive electrode under a large number of low-momentum collisions (electron wind). Also, energetic electrons are capable of breaking bonds by exciting the bonding electrons through the collision. In fact both field-enhanced diffusion under electric force and electron bombardment effects are responsible for the enhanced crystallization in FAMIC. In both mechanisms, the diffusion of metal is a common argument. Grisenti et al. (Grisenti et al., 2008) reported the Extended x-ray absorption fine structure (EXAFS) analysis on Ni induced $a$-Si produced by co-sputtering. They came to conclusion that, $\mathrm{Ni}$ segregates as $\mathrm{NiSi}_{2}$ even at temperatures as low as $200{ }^{\circ} \mathrm{C}$ and this $\mathrm{NiSi}_{2}$ enhances the MIC of $a$-Si. The transformation from one kind of silicide to other is well explained by Ni diffusion through $\mathrm{Ni} / \mathrm{Si}$ interface and this mechanism is widely accepted in the semiconductor technology.

\subsection{Metal Induced Lateral Crystallization (MILC)}

In case of MILC first metal silicides are formed at the interface between metal and Si layers at the lower annealing temperatures. On further annealing, nucleation of c-Si on metal silicide precipitate starts, which is then followed by migration of the metal silicide precipitates throughout the a-Si thin film, resulted in crystallization of the entire a-Si film. This mechanism is supported by the following experimental observations. Jin et al. (Jin et al, $1998)$ studied the XPS depth profile of $\mathrm{Ni}(10 \mathrm{~nm})$ covered a-Si films $(70 \mathrm{~nm})$ which was annealed at $500 \mathrm{C}$ for $1 \mathrm{hr}$. Ar ions with energy of $4 \mathrm{keV}$ were used for sputtering during depth profiling. They reported the concentration variation of selected elements $(\mathrm{Ni}, \mathrm{O}$ and $\mathrm{Si}$ ) across the $100 \mathrm{~nm}$ stack. From their results it is found that the Ni concentration first decreased with Ar sputtering then stabilized to about $4 \%$ in the bulk of the film and finally increased to about $10 \%$ near the interface of the film. No Si was detected on the surface of the stack before the Ar sputtering, indicating the diffusion of $\mathrm{Si}$ in $\mathrm{Ni}$ and $\mathrm{NiO}_{x}$ was slow at the heat treatment temperature of $500{ }^{\circ} \mathrm{C}$. The presence of excess metallic $\mathrm{Ni}$ at the bottom of the stack was attributed to the diffusion of the $\mathrm{NiSi}_{2}$ nodules. Hayzelden et al. (Hayzelden \& Batstone, 1993) reported an in-situ transmission electron microscopy study on Ni induced $a$ $\mathrm{Si}$ crystallization and suggested a similar mechanism for the diffusion of $\mathrm{NiSi}_{2}$ in $a$-Si matrix. According to the mechanism proposed by these authors, Si first crystallizes on one of the eight faces of $\mathrm{NiSi}_{2}$ crystalline seeds and then it dissociates as $\mathrm{Ni}$ and $\mathrm{Si}$ atoms at the $c-\mathrm{Si}$ / $\mathrm{NiSi}_{2}$ interface. The Nickel atoms then diffuse and react again with $a-\mathrm{Si}$ to form $\mathrm{NiSi}_{2}$ at $a-\mathrm{Si}$ / $\mathrm{NiSi}_{2}$ interface. The cause of such dissociation, diffusion and reformation of $\mathrm{NiSi}_{2}$ was explained by chemical potential free energy of the reactions at different interfaces. The chemical potential of $\mathrm{Ni}$ is lower at $\mathrm{NiSi}_{2}$ /a-Si interface, while the chemical potential of $\mathrm{Si}$ is lower at the $\mathrm{NiSi}_{2}$ / c-Si interface. Thus $\mathrm{Ni}$ moves to the $\mathrm{NiSi}_{2} / \mathrm{a}-\mathrm{Si}$ interface and $\mathrm{Si}$ atoms are froced to diffuse to the $\mathrm{NiSi}_{2} / \mathrm{c}-\mathrm{Si}$ interface. The consumption of a-Si at the $\mathrm{NiSi}_{2} / \mathrm{a}-\mathrm{Si}$ interface and diffusion of the $\mathrm{Ni}$ atoms result in the growth of needle like $\mathrm{Si}$ crystallites. The diffusion of $\mathrm{Ni}$ in crystalline $\mathrm{Si}$ is much faster than that in a-Si. This supports the fast diffusion of $\mathrm{Ni}$ from the c-Si interface to the a-Si interface through a $\mathrm{NiSi}_{2}$ crystallite. Hwang et al. (Hwang \& Li, 2005) studied the Auger depth profile on Ni induced MIC and came to a similar conclusion. Our recent work on the transmission electron microscopy study of $\mathrm{Ni}$ induced MIC of a-Si films also supports the $\mathrm{NiSi}_{2}$ diffusion mechanism. The details of the experiment and result are presented in the section 4.2 of the chapter. 


\section{Tin induced a-Si crystallization}

Tin is a representative of the eutectic forming group along with $\mathrm{Al}$ and $\mathrm{Au}$. The $\mathrm{Sn}-\mathrm{Si}$ alloy has a relatively low eutectic temperature of $232{ }^{\circ} \mathrm{C}$ (Jeon et al., 2010) compared other members of the group. Our recent work on Tin induced a-Si revealed that it follows the eutectic forming metal mechanism well below the Al-Si system (Mohiddon \& Krishna, 2011). Jeon et al. (Jeon et al., 2010) studied the Sn-Si system for growing Si nanowires and quoted that $\mathrm{Sn}$ is a favorable catalyst for low temperature synthesis of $\mathrm{Si}$ nanowires.

The experimental details are as follows. Sn films of $500 \mathrm{~nm}$ thickness were deposited onto Borosilicate Glass (BSG) substrates by resistive thermal evaporation. Si films of $500 \mathrm{~nm}$ thickness were deposited by electron beam evaporation over the Sn layers. Fig. 1 shows the block diagram of experimental deposition setup of electron beam evaporator and block diagram of film annealing setup. The starting materials were granular pure silicon powder $(99.999 \%)$ and Sn $\left(99.99 \%\right.$ pure). A pressure $5 \times 10^{-6}$ Torr was maintained throughout the depositions. The depositions were carried out at ambient temperature and in all cases the substrate to source distance was kept constant at $10 \mathrm{~cm}$. The thickness of the films was measured after deposition using a surface profilometer (model XP-1 of Ambios Technology, USA). The films were annealed in a furnace atmosphere at different temperatures for $1 \mathrm{hr}$. X-ray diffraction patterns were recorded on a powder x-ray diffractometer (CPS120 of Inel, France) machine equipped with a Co Ka x-ray source (wavelength $=0.178896 \mathrm{~nm}$ ) and gas phase position sensitive detector.
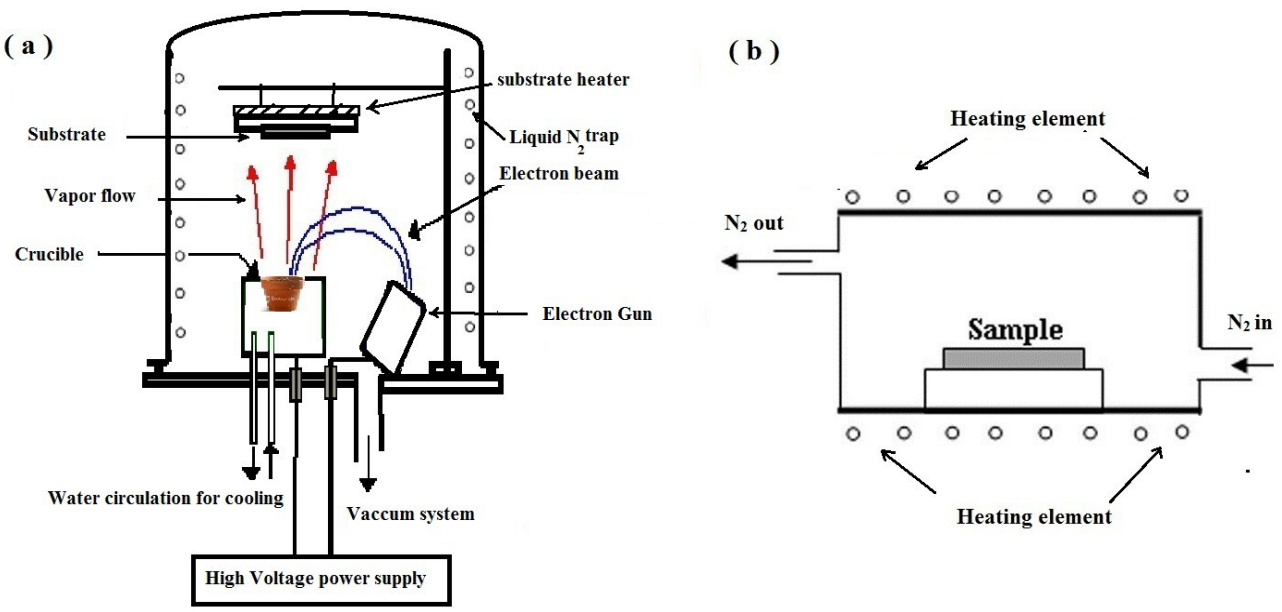

Fig. 1. Schematic diagram of (a) film deposition by Electron beam evaporator (b) annealing of the film in muffle furnace

X-ray diffraction patterns of as deposited BSG/Sn/a-Si stacks and stacks post deposition annealed at different temperatures from $300{ }^{\circ} \mathrm{C}$ to $500{ }^{\circ} \mathrm{C}$ each for 1 hour are presented in Fig. 2. XRD pattern of Sn film deposited on BSG and annealed at $500{ }^{\circ} \mathrm{C}$ for $15 \mathrm{hrs}$ is also presented in the same figure. It is evident from the XRD pattern of the annealed Sn film that, it is well crystallized and the pattern can be identified as belonging to the orthorhombic phase of $\mathrm{SnO}_{2}$ (the peaks were indexed according to the PCPDF file no-781063). The as 
deposited BSG/Sn/a-Si stack, shows sharp diffraction peaks along with a broad diffuse hump around $2 \theta=27 \mathrm{o}$, due to the amorphous substrate and $a$-Si film. The peaks can be assigned to the (200), (101), (220), (211), (112) and (312) planes of the tetragonal phase of metallic Sn (the peaks are indexed according to the PCPDF file no- 23456). There is no evidence for the presence of crystalline Si.

On annealing this stack at $300{ }^{\circ} \mathrm{C}$ for $1 \mathrm{hr}$, there is a very interesting transformation in the crystalline behavior of the films. Significantly, all the peaks due to metallic $\mathrm{Sn}$ are completely suppressed and the x-ray diffraction pattern resembles that of an amorphous film except for a very diffuse peak at $2 \theta=33.58^{\circ}$ assigned to the (111) plane of the diamond cubic form of $\mathrm{Si}$. The intensity of this peak increases with increasing annealing temperature up to $500{ }^{\circ} \mathrm{C}$ as shown in Fig. 2 indicating that the extent of crystallization of $\mathrm{Si}$ is improved by increasing the annealing temperature. However, there is no evidence for crystalline $\mathrm{Sn}$ in the films. The reason for this is, most probably, partial oxidation of Sn. The peak at $2 \theta=$ $33.58^{\circ}$ assigned to the (111) plane of diamond cubic silicon (PCPDF file no- 23345) is shifted by $0.45^{\circ}$ which is attributable to strain in the film. Evidently, the onset of crystallization of $a$ $\mathrm{Si}$ occurs at $300{ }^{\circ} \mathrm{C}$ by contacting with the $\mathrm{Sn}$ metal. M Joen et al. have also reported Sn induced crystallization of $a-\mathrm{Si}$ at $300{ }^{\circ} \mathrm{C}$ (Jeon et al., 2010). Significantly, there is no evidence for the formation of silicides in the $\mathrm{Sn}$-Si system even after annealing at $500{ }^{\circ} \mathrm{C}$. Deconvolution of the peak at $2 \theta=33.58^{\circ}$ provides more insight into the mechanism of crystallization of $a$-Si. The peak was deconvoluted by smoothening and best fitting with a Gaussian function. The data is shown in the inset of Fig. 2 for the samples annealed at 300, 400 and $500{ }^{\circ} \mathrm{C}$. Closer observation of the peak corresponding to the sample annealed at 500 ${ }^{\circ} \mathrm{C}$ shows that the peak can be resolved into two peaks centered at 33.7 and $34{ }^{\circ}$. The deconvoluted peaks fitted using Gaussian function is shown in the inset of the Fig 2. The peak centered at $2 \theta=34^{\circ}$ is assigned to the (113) plane of orthorhombic $\mathrm{SnO}_{2}$ phase (PCPDF file no- 781063). By eliminating the effect of $\mathrm{SnO}_{2}$ phase in $500{ }^{\circ} \mathrm{C}$ annealed samples, the crystallite size is estimated as $18 \mathrm{~nm}$. The average nanocrystal size calculated by Scherrer's equation (Mohiddon \& Yadav, 2008) is found to increase from $5 \mathrm{~nm}$ to $14 \mathrm{~nm}$ with increasing the annealing temperature from 300 to $400{ }^{\circ} \mathrm{C}$. The solid solubility of $\mathrm{Sn}$ in $\mathrm{Si}$ is known to be nil, i.e. they are immiscible in the solid state (Leonard \& Koch, 1992). Hence it is not expected to form a silicide. X-ray diffraction data presented earlier indicates that this is the case even in the present samples. The crystallographic evolution of the c-Si phase in the current case is traced by studying the dependence of the crystallite size of Sn and Si on the annealing temperature. This is plotted in Fig. 3, from which it is evident that the crystallite size of $\mathrm{Si}$ is zero in the as-deposited film while that of the $\mathrm{Sn}$ phase is high. Interestingly, there is a cross-over region below $300{ }^{\circ} \mathrm{C}$ when the crystallite sizes of both phases are low. This indicates that at this temperature, the film is essentially amorphous. On increasing the annealing temperature to 400 and $500{ }^{\circ} \mathrm{C}$, there is further increase in the crystallite size of $\mathrm{Si}$ while crystallite size of the $\mathrm{Sn}$ phase is invariant at zero. This behavior is very similar to that observed in the case of Al induced crystallization (AIC) of a-Si (McCaldin \& Sanku, 1971; Zener,1949;Spinella et al.,1998) with one very crucial difference. No peaks corresponding to crystalline Sn are observed on annealing the films unlike the AIC case. This is evidently due to oxidation of Sn during the annealing process as revealed by the deconvolution of the (111) peak of $\mathrm{Si}$ in the inset of Fig.2. Thus we conclude from this work that $a$-Si crystallizes when it is brought in contact with Sn metal layer without involving the formation of a silicide, exactly as followed by eutectic forming metals at $300^{\circ} \mathrm{C}$. 


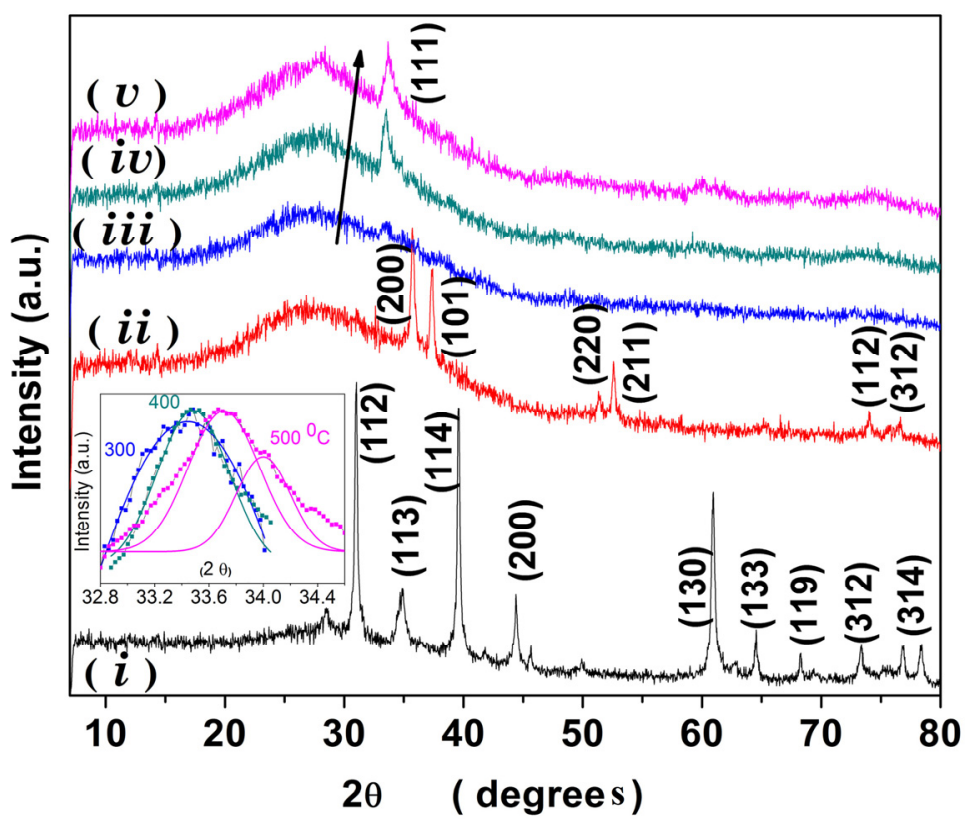

Fig. 2. X-ray diffraction pattern of (i) BSG/Sn film annealed at $500{ }^{\circ} \mathrm{C}$ for 15 hours. (ii) asdeposited BSG/Sn/a-Si stack and BSG/Sn/a-Si stack annealed at (iii) 300, (iv) 400 and (v) $500{ }^{\circ} \mathrm{C}$ along with the expanded and smoothened (111) peak of $c$-Si for BSG/Sn/a-Si stack, deconvoluted to show the presence of $\mathrm{SnO}_{2}$ (Mohiddon et al., 2012).

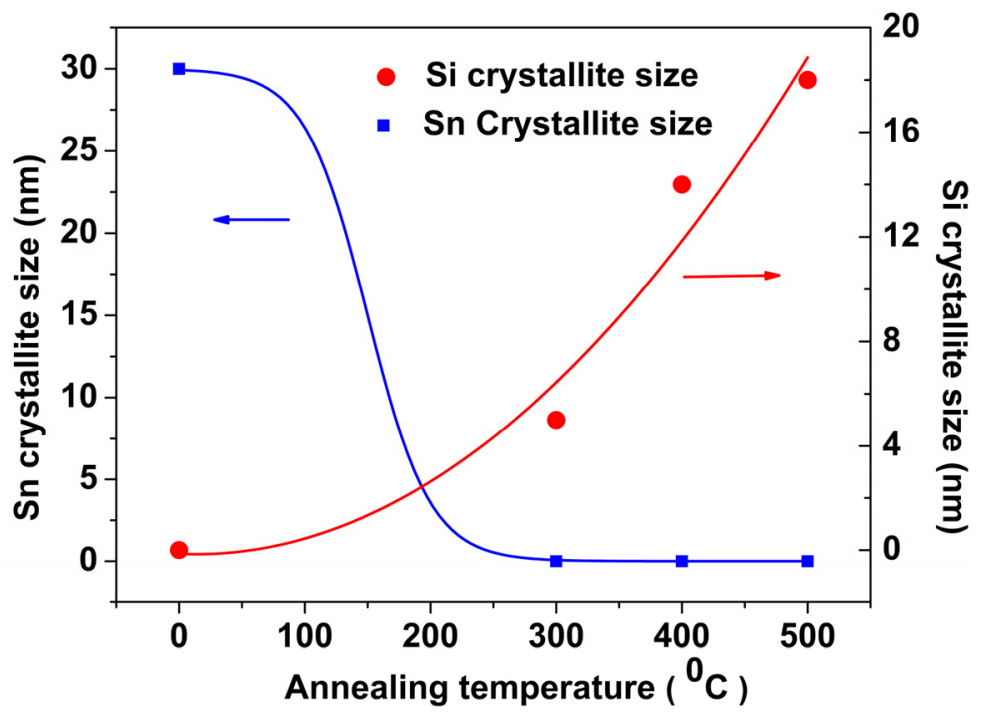

Fig. 3. Variation in crystallite size of $\mathrm{Si}$ and $\mathrm{Sn}$ phases as a function of annealing temperature (Mohiddon et al., 2012). 


\section{Nickel and Chromium induced crystallization}

The second group of metals used for MIC, reacts with silicon and forms silicides. e.g.: $\mathrm{Ni}, \mathrm{Cr}$, $\mathrm{Pd}$, Mo etc. A very small concentration of metals contamination crystallizes large part of $a$-Si and hence they are highly useful in electronic applications. In this section we review our work on Nickel and Chromium induced crystallization of amorphous Si films.

\subsection{Nickel induced crystallization}

Nickel induced MIC is one of best representatives of this group. To investigate Nickel based MIC, two types of experiments were carried out. In the first case, a $400 \mathrm{~nm} a$-Si film is deposited on a fused silica (FS) substrate followed by $200 \mathrm{~nm} \mathrm{Ni}$ film forming a FS/a$\mathrm{Si}(400 \mathrm{~nm}) / \mathrm{Ni}(200 \mathrm{~nm})$ (FSN) stack. The depositions were carried out at different substrate temperatures from 200 to $400{ }^{\circ} \mathrm{C}$. After the deposition is completed, the films were annealed in the vacuum, in the same chamber without removing the vacuum for $30 \mathrm{~min}$ at the deposition temperature. The second growth process involves the deposition of $200 \mathrm{~nm} \mathrm{Ni}$ films on fused silica (FS) substrates followed by deposition of $400 \mathrm{~nm}$ amorphous Si films at $200{ }^{\circ} \mathrm{C}$ substrate temperature, forming a FS/Ni(200nm)/a-Si(400nm) (FNS) stack.

All films were deposited by the electron beam evaporation technique. The starting materials were granular pure silicon powder $(99.999 \%)$ and nickel powder (99.99\% pure). The vacuum chamber was evacuated using a diffusion-rotary pump combination equipped with a liquid nitrogen trap. A pressure $5 \times 10^{-6}$ Torr was maintained throughout the depositions. In all cases the substrate to source distance was kept constant at $10 \mathrm{~cm}$. The thickness of the film is measured after deposition using a surface profilometer (model XP-1 Ambios Tech., USA). Xray diffraction patterns were recorded on a powder x-ray diffractometer (CPS120 of Inel, France) machine equipped with a $\mathrm{Co} \mathrm{K} a=0.178896 \mathrm{~nm}$ and gas phase position sensitive detector. XAFS measurements on the FNS stacks were performed at the Ni K-edge at 8333 $\mathrm{eV}$, in fluorescence mode at two different incidence geometries. The two incident angles are $2^{\circ}$ and total reflection (TR) geometries. In total reflection geometry only few nanometers of top layer are monitored (10 to $20 \mathrm{~nm}$ ). At 2 degree incident angle, the entire thickness of the film is under focus. The radiation source was the European Synchrotron Radiation Facility (ESRF, Grenoble, France) and XAS measurements were performed at the BM08 (GILDA) beamline, with an average storage ring current of $180 \mathrm{~mA}$. Data are collected in fluorescence mode using a 13- element hyper pure Ge detector.

Figure 4 shows the X-ray diffraction pattern (XRD) of FS/ a-Si / Ni (FSN) stack deposited at different substrate temperatures. The FSN stack deposited at 200 and $300{ }^{\circ} \mathrm{C}$, shows similar XRD pattern. These XRD patterns, indexed according to the PCPDF file no -701849 and refined using Powder $X$ software, are identified as belonging to face centred cubic (FCC) structure of metallic Nickel. The refined FCC unit cell parameter is $a=3.53 \AA$. No change in the unit cell parameter is observed for the samples deposited at 200 and $300{ }^{\circ} \mathrm{C}$. In the FSN stack deposited at $400{ }^{\circ} \mathrm{C}$, it is observed that, a new set of XRD peaks are grown along with the metallic Ni XRD peaks. These new set of peaks belong to the face centre cubic structure of $\mathrm{NiSi}_{2}$ indexed according to the PCPDF file no-652974. The FCC unit cell parameter of metallic Ni calculated using (111) peak is found to be $3.52 \AA$ and that of $\mathrm{NiSi}_{2}$ using (111) peak is $5.36 \AA$. There is no change in the unit cell parameter of metallic Ni for the samples 
deposited at 300 and $400{ }^{\circ} \mathrm{C}$. The small change of $0.01 \AA$ is considered within the range of instrumental measurement error. The disagreement of our result with that of I. H. Hong et al. (Hong et al., 2006) work is expected to be due to the ultra high vacuum pressure deposition conditions, which may facilitate the reaction of the diffused metallic $\mathrm{Ni}$ atoms at lower temperature to form different silicide phases.

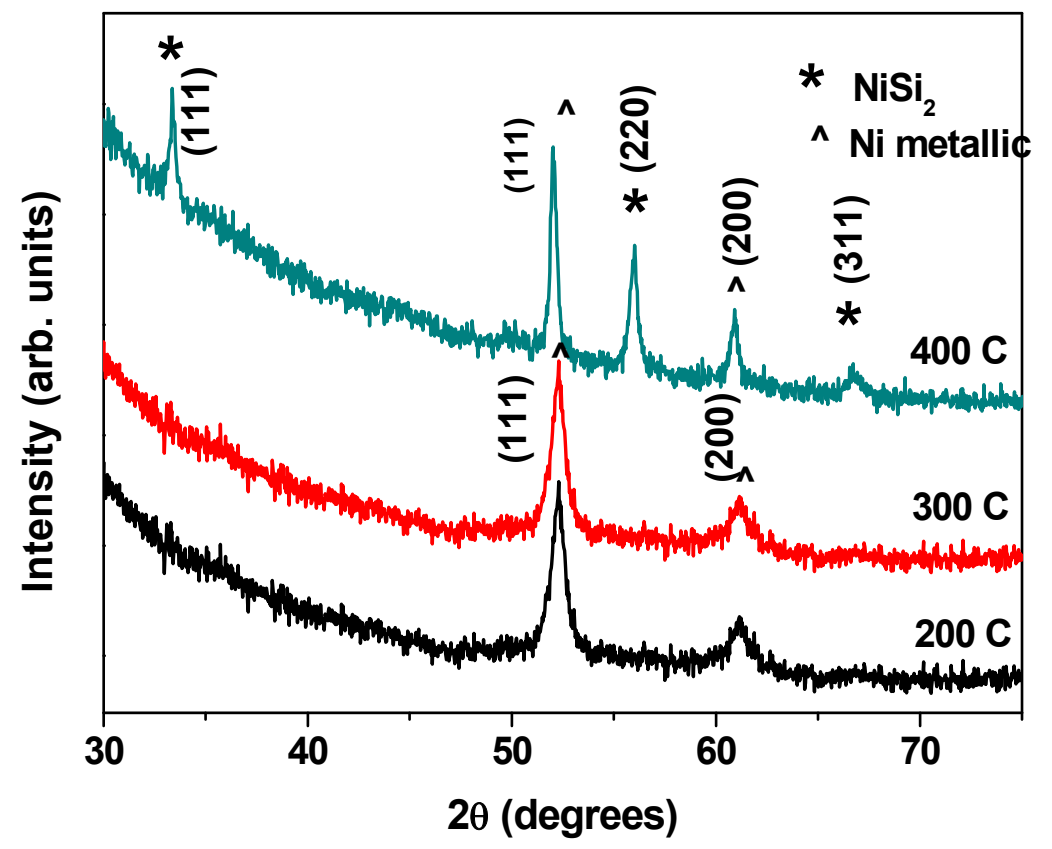

Fig. 4. XRD pattern of FS/Si/Ni stack deposited at different substrate temperature

Figure 5(a) compares the experimental XAFS spectrum of Ni K edge in the FNS stack, which were measured in two different incident angles (TR and 2 degree), along with the reference metal Ni foil spectra. The first derivative near the XANES region of the spectra is presented in the inset of the Fig. 5(a). The observation of the inset figure shows that the XANES spectra of FNS stack deposited at $200{ }^{\circ} \mathrm{C}$ and measured in TR and 2 degree has a resemblance with that of the metallic Ni reference spectra. The qualitative analysis of the XAFS spectra shows that the nature of Ni impurity measured in TR and 2 degree are similar and has close resemblance with that of the metallic $\mathrm{Ni}$. Thus at $200{ }^{\circ} \mathrm{C}$ annealing temperature the metallic $\mathrm{Ni}$, which is deposited at the bottom, is diffused through $400 \mathrm{~nm}$ a-Si layer. The similar observation is found in the EXAFS part of the spectra. Figure 5 (b) compares the Fourier Transform (FT) of the EXAFS signal at the $\mathrm{K}$ edge of Ni presented for the FNS stack deposited at $200{ }^{\circ} \mathrm{C}$ and measured in two different incident angles, along with the metallic Ni. It shows that the FNS stack deposited at $200{ }^{\circ} \mathrm{C}$ and measured in two different incident angles has the features of metallic $\mathrm{Ni}$. The detailed quantitative analyses were carried by FEFF8 and FEFFIT theoretical code and are presented elsewhere (Mohiddon et al., 2011). The conclusions of the work are in good agreement with that of the qualitative analysis 
presented above. Thus the EXAFS work carried on the FNS spectra support the Ni diffusion assisted MIC mechanism.
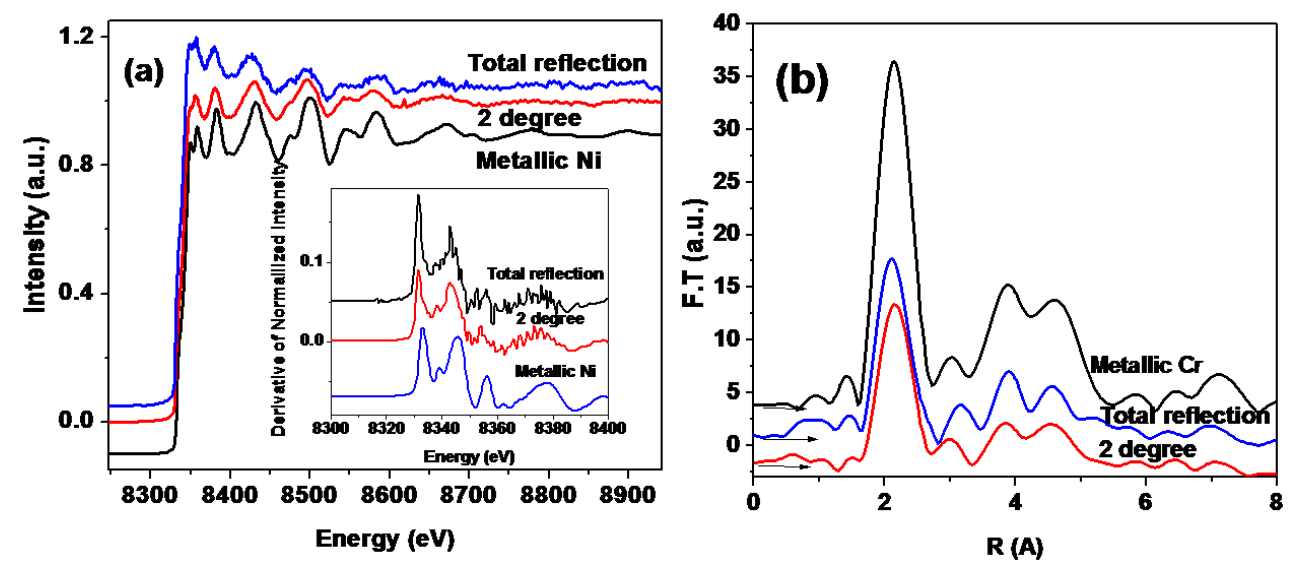

Fig. 5. (a) X-ray absorption spectra along with its derivative near XANES in the inset (b) F.T of EXAFS part of FS/Ni/a-Si stack deposited at $200{ }^{\circ} \mathrm{C}$ measured in total reflectance and 2 degree along with metallic Ni reference compound.

\section{2 $\mathrm{Ni}$ induced Lateral Crystallization (NILC)}

As discussed in Sec 2.3, in case of MILC first metal silicides are formed at the interface between metal and Si layers at the lower annealing temperatures. On further annealing, nucleation of c-Si on metal silicide precipitate starts, which is then followed by migration of the metal silicide precipitates throughout the a-Si thin film, resulted in crystallization of the entire a-Si film. We have carried a detailed transmission electron microscope study and found similar observation. The details of the experiment are as follows. The Ni and Si films are deposited using electron beam evaporation at 4x10-6 Torr and ambient temperature onto Si (311) substrates. The starting materials were granular pure silicon powder $(99.999 \%)$ and nickel powder (99.99\% pure). The (311) oriented Si wafer was well cleaned and subjected to heat treatment of $1000{ }^{\circ} \mathrm{C}$ for 2 hours in normal furnace atmosphere to form a thick $\mathrm{SiO}_{2}$ layer, before the deposition is started. $\mathrm{The}_{\mathrm{SiO}}$ layer is expected to act as a barrier to stop the diffusion of $\mathrm{Ni}$ atom into the $\mathrm{Si}$ substrate. X-ray diffraction patterns were recorded in grazing incidence of 0.5 degree on a powder x-ray diffractometer (CPS120 of Inel, France) machine. A $50 \mathrm{~nm}$ film of $\mathrm{Ni}$ was deposited on the $c-\mathrm{Si} / \mathrm{SiO}_{2}$ substrate, followed by the deposition of the $400 \mathrm{~nm}$ Si film without breaking vacuum in the deposition chamber. The thickness of the films was measured after deposition using a surface profilometer (model XP-1 Ambios Tech., USA). The films were subsequently annealed in a furnace (in air) at 600 ${ }^{\circ} \mathrm{C}$ for $1 \mathrm{hr}$. Transmission electron micrographs were obtained by a Tecnai 20 G2 STwin, FEI electron microscope, operated at $200 \mathrm{kV}$. Electron diffraction patterns (EDPs) were recorded with a Gatan CCD camera. A $10 \mathrm{~nm}$ gold film deposited on the grid was used for purpose of camera length calibration. The samples for TEM measurement were prepared by scratching the film and transferring it on to the grid. 
Figure 6 is a bright-field transmission electron micrograph obtained from a region of the $\mathrm{Ni} / \mathrm{Si}$ thin film crystallized by the MIC process. The typical microstructure shown in Fig. 6 consists of dark region with an irregular shape. The microstructure consists of dark dendrite like nanowire structures spread over the bright looking matrix. To find the nature of nanostructures at two different regions of the sample, selected area electron diffraction (SAED) patterns were recorded at both the dark and bright regions of the sample. A typical diffraction pattern from the dark part of the image is shown in the inset of the Fig. 6 . The diffraction pattern consists mainly of bright diffraction spots radially positioned on rings. The diffraction spots arise from the crystalline part of the sample, whereas the ring originates from the polycrystalline parts of the sample. The inset of the Fig 6 shows that, the diffraction spots A, B and C lie on the polycrystalline ring of radius $0.314 \mathrm{~nm}$, which is indexed to the (111) plane of the Silicon diamond cubic phase. The spot D has a $d=0.185 \mathrm{~nm}$ which can be indexed as belonging to the $(2 \overline{2} 0)$ plane of the diamond cubic system [JCPDS892955]. However, an alternative assignment is possible for the same diffraction spots (and the higher order diffraction spots), because they can be equally assigned to the face centred cubic $c-\mathrm{NiSi}_{2}$, with $d$ values of $0.312 \mathrm{~nm}, 0.191 \mathrm{~nm}$ for (111) and $\left(2 \frac{\overline{2}}{2}\right)$ planes, respectively [JCPDS-652974]. Hence, the diffraction taken in dark region of the sample shown in Fig 6 may belong either to diamond cubic $\mathrm{Si}$ or to face centre cubic $\mathrm{NiSi}_{2}$.

The diffraction pattern from the bright area region is shown in other inset of Fig.6. Even at the higher magnifications, the microstructure of this bright region is seen to contain dark dendritic lines. It was thus inpossible to eliminate the presence of the darker regions. Hence, the diffraction pattern shown in second inset of Fig 6 has a combined effect, with a small contribution from dark nanostructures and large contribution from the bright area. The diffraction pattern is slightly different from that of dark region diffraction pattern. It consists of one diffuse diffraction rings with $\mathrm{d}=0.314 \mathrm{~nm}$ and a bright diffraction spots with $\mathrm{d}=0.192$ $\mathrm{nm}$ (indicated by E). There are, however, no diffraction spots disposed on the ring, thus suggesting that the dark region is better crystallized compared to bright region although both the regions show similar diffraction patterns.

To exactly identify the material(s) that are contributing to the diffraction from the bright and dark regions of the samples, $Z$ (atomic number)-contrast scanning transmission electron microscopy (STEM) study was carried out. Fig. 7 is a Z-contrast STEM image of the same selected area that is shown in Fig. 6 . The change in contrast in the image is due to change in $Z$ value of $\mathrm{Ni}(Z=28)$ and $\mathrm{Si}(Z=14)$. This observation suggests that the central high contrast region is due to the contribution from $\mathrm{Ni}$ component, i.e. $\mathrm{NiSi}_{2}$ and the low contrast region is from $\mathrm{Si}$. Hence, it can be inferred that the $\mathrm{NiSi}_{2}$, after its formation, starts spreading through the matrix of $a$-Si like a dendrite and leading to its crystallization. The results presented in this part of the study supports the mechanism of movement of $\mathrm{NiSi}_{2}$ dendrites in the $a-\mathrm{Si}$ matrix as the cause for crystallization. Similar movement of $\mathrm{Cu}_{3} \mathrm{Si}$ dendrites with time of annealing was reported using in-situ bright field transmission electron microscopy, but no diffraction study was reported (Russell et al.,1991). It is evident from the study of SAED and STEM, that when Ni makes contact with the Si layer at high temperature it forms $\mathrm{NiSi}_{2}$. This silicide starts diffusing as dendrites into the $a$-Si matrix and crystallizes the silicon at the nanoscale. This strongly supports the mechanism of silicide movement as the basis for crystallization of $a$-Si by the MILC process using silicide forming metals. 


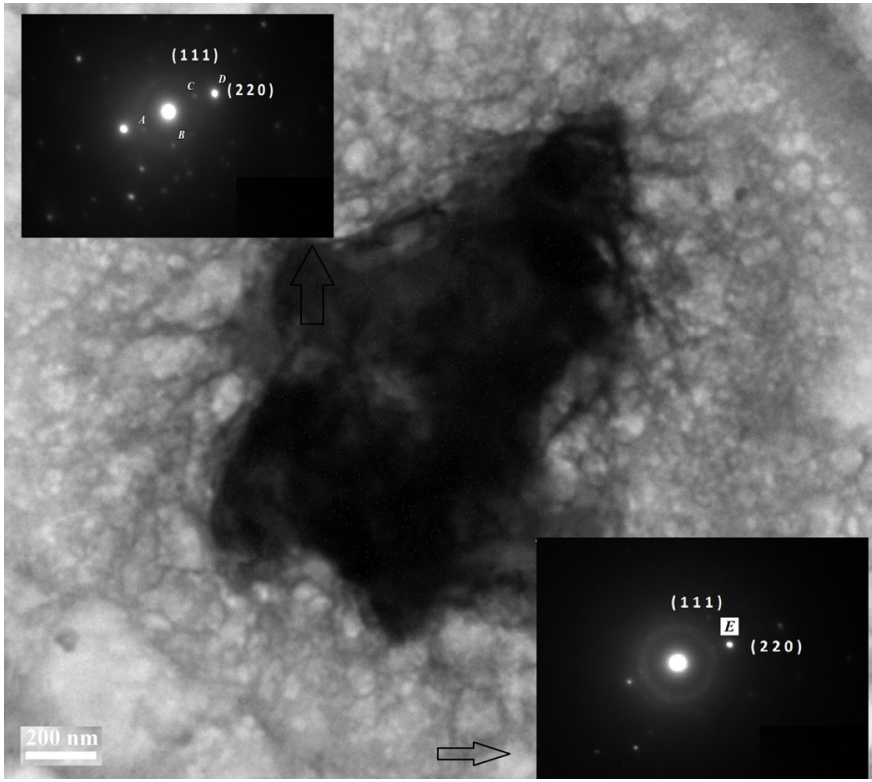

Fig. 6. Selected Bright field image of Ni/Si film annealed at $600{ }^{\circ} \mathrm{C}$ for $1 \mathrm{hr}$ along with the diffraction pattern in the dark and bright regions (Mohiddon et al., 2012).

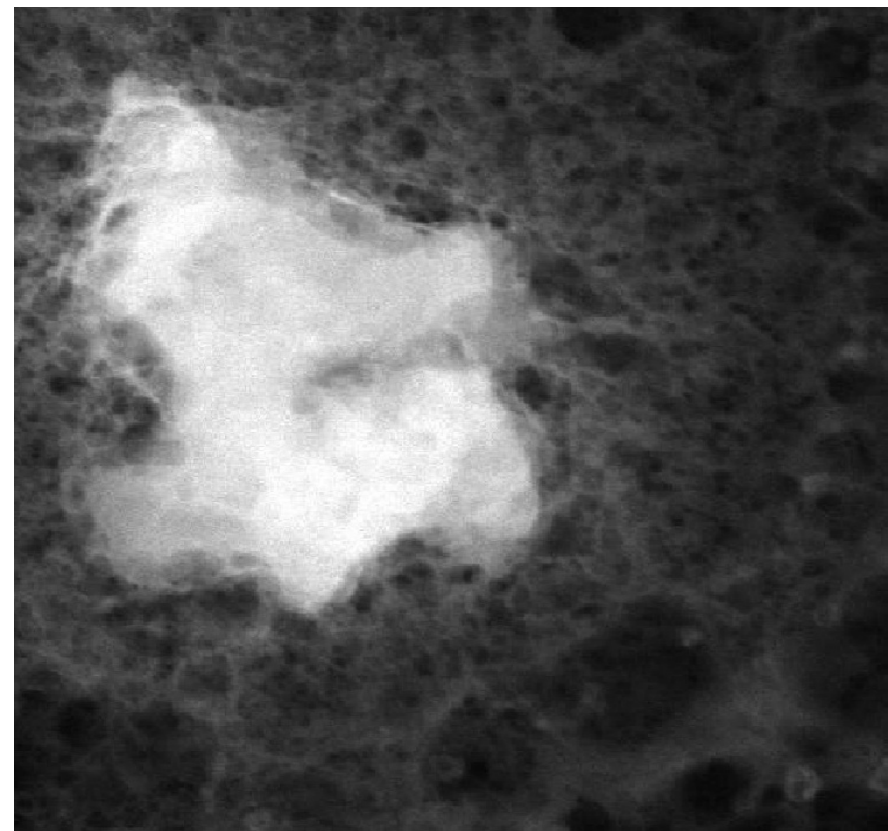

Fig. 7. STEM image of $\mathrm{Ni} / \mathrm{Si}$ film annealed at $600^{\circ} \mathrm{C}$ for $1 \mathrm{hr}$, selected the same region as that selected for bright field image in Fig. 6 (Mohiddon et al., 2012). 


\subsection{Stabilization of wurtzite Si}

Silicon (Si) usually crystallizes in the cubic diamond structure with fourfold coordinated symmetry. Numerous high-pressure experiments have been performed, revealing no less than 12 different polymorphs of silicon between the well characterized diamond cubic phase and theoretically intractable amorphous phase. With the release of pressure several metastable phases are observed (Wu et al., 2000). For example, a nonmetal to metal transition of cubic-diamond phase, which occur by changing pressure from ambient atmosphere pressure to $10-13 \mathrm{GPa}$ to form a $\beta$-tin structure, which further transforms to rhombohedral phase on slow pressure release. The latter transforms reversibly at a pressure of $2 \mathrm{GPa}$ to a body-centered-cubic phase (bc8). Hexagonal-wurtzite silicon ( $w$-Si) can be formed by heating the bc 8 phase to above $200^{\circ} \mathrm{C}$, or directly from the cubic-diamond phase in the presence of shear stresses at twin intersections, or a nonhydrostatic stress of $8 \mathrm{GPa}$ in indentation experiments (Kailer et al., 1997). $w$-Si material is rarely studied by spectroscopic measurements, because it cannot be obtained in a stable phase. Zhang et al. (Zhang et al., 1999 ) produced stable $w$-Si phase by laser ablation. Its identification by electron diffraction has been confirmed by micro Raman spectroscopy. Bandet et al. (Bandet et al., 2002) deposited $w$-Si during elaboration of $\mathrm{SiO}_{2}$ thin films and reported that oxygen seems to play a crucial role in the stabilization of the uncommon metastable structure. Kim et al. (Kim \& Lee, 1996) reported that the micrometer-sized diamond cubic silicon (c-Si) crystals contain minority part of hexagonal silicon, when $a$-Si films crystallized by a pulsed laser. In the present work we have crystallized the silicon film with a metal contact and found that silicon nanocrystals are in wurtzite phase. The experimental details are as follows.

Nickel and Silicon films were deposited by electron beam evaporation on to BoroSilicate Glass (BSG) substrates in high vacuum of the order of $10^{-6}$ Torr. First a $50 \mathrm{~nm}$ thin nickel blanket bottom layer was deposited on BSG substrates maintained at ambient temperature. This is followed by the deposition of a $700 \mathrm{~nm}$ thick Si film, without breaking vacuum, to form a BSG/Ni/Si stack. The thickness of the films is measured after deposition using a surface profilometer (model XP-1 Ambios Tech., USA). The films were annealed in a furnace atmosphere (in air) at $550^{\circ} \mathrm{C}$ for $1 \mathrm{hr}$. Transmission electron micrographs were obtained by a Tecnai 20 G2 STwin, FEI electron microscope, operated at $200 \mathrm{kV}$. Electron diffraction patterns (EDPs) were recorded with a Gatan CCD camera. A $10 \mathrm{~nm}$ gold film deposited on the grid was used for camera length calibration purposes. The Raman spectra were recorded in air using an Nd-YAG 532nm laser in the back scattering geometry in a CRM spectrometer equipped with a confocal microscope and $100 \times$ objective $(1 \mu \mathrm{m}$ diameter focal spot size) with a CCD detector (model alpha 300 of WiTec Germany). The phase content with in the samples was investigated in a spectral region $200-1500 \mathrm{~cm}^{-1}$.

Figure 8 shows the electron diffraction pattern along with a bright-field transmission electron micrograph obtained from a region in the silicon thin film crystallized by a MIC process in the inset. The typical microstructure shown in inset of Fig. 8 consists of spherical particles with approximate diameter of $40 \mathrm{~nm}$. The diffraction spots can be identified as belonging to well defined orientations. The calculated interplanar distances of the lattice planes at different spots of the diffraction pattern assigned by symbols $\mathrm{A}, \mathrm{B}$ and $\mathrm{C}$ in Fig. 8 are $A=0.256 \mathrm{~nm}, B=0.237 \mathrm{~nm}$ and $C=0.237 \mathrm{~nm}$ respectively. From the calculated interplanar distances the diffraction spots were indexed as $\left(\begin{array}{lll}1 & 0 & 0\end{array}\right),\left(\begin{array}{lll}1 & \overline{1} & 1\end{array}\right)$, and $\left(\begin{array}{lll}\mathrm{O} & \overline{1} & 1\end{array}\right)$, which belong to 
the $[1 \overline{2} 13]$ zone axis. These diffraction spots were diffracted from a grain which has a

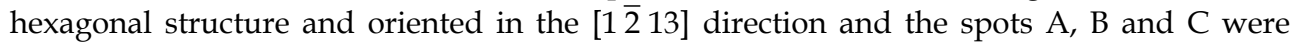
diffracted from the $\left(\begin{array}{lll}1 & 0 & 0\end{array}\right),\left(\begin{array}{lll}1 & \overline{1} & 1\end{array}\right)$, and $\left(\begin{array}{lll}O & \overline{1} & 1\end{array}\right)$ planes, respectively. The corresponding lattice parameters were calculated as $a=0.296 \mathrm{~nm}, c=0.629 \mathrm{~nm}$ with $c / a$ ratio of 2.13 . The angle calculated between these planes using $c / a$ value is found to be exactly matching with the measured values suggesting that $\mathrm{Si}$ crystallizes in the hexagonal structure. For diamond cubic Si crystals the interplanar distances of the lattice planes should be $0.331 \mathrm{~nm}, 0.331 \mathrm{~nm}$ and $0.331 \mathrm{~nm}$, respectively and the angles between transmitted beam and the spots will be $60^{\circ}, 60^{\circ}$ and $60^{\circ}$, with the diffraction pattern showing the expected six fold symmetry. But in our case the angles between the dots are $\angle \mathrm{AOB}=65^{\circ}, \angle \mathrm{BOC}=55^{\circ}$ and $\angle \mathrm{AOC}=120^{\circ}$ respectively, clearly not cubic Si. Thus, the TEM analysis shows that the BSG/Ni/Si stack after heat treatment consists of $40 \mathrm{~nm}$ particles of hexagonal Silicon with $c / a$ ratio of 2.11.

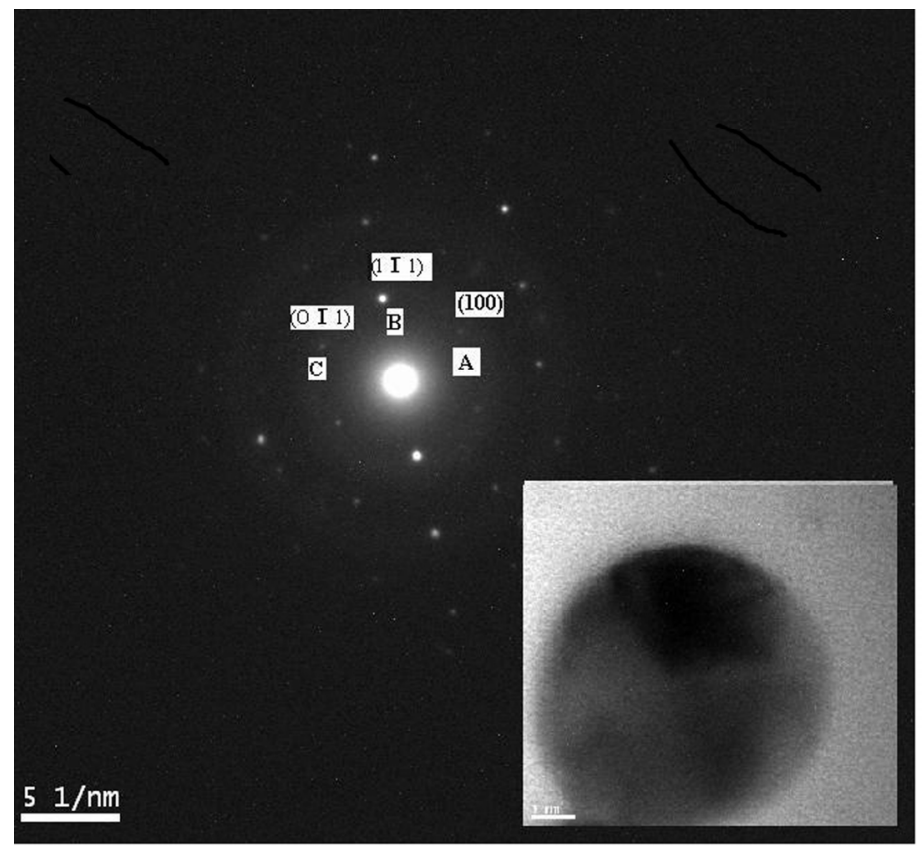

Fig. 8. Electron diffraction pattern along with indexing of selected w-Si part of BSG/Ni/Si stack, inset shows the bright field image of the above diffraction area (Mohiddon et al., 2011).

Additional evidence for the formation of $w$-Si is provided in the form of Raman spectra of the films. It has earlier been used to characterize porous Si (Sui et al., 1992) and Si nanostructures (Kozlowski et al., 1991). The Raman shift and the shape of the Raman peak yield information on the degree of crystallinity achieved in Si by MIC process. Fig. 9 shows Raman spectra from the Silicon film annealed at $550^{\circ} \mathrm{C}$ for $1 \mathrm{hrs}$. A sharp peak at $504 \mathrm{~cm}^{-1}$ and weak broad peaks around 300 and $950 \mathrm{~cm}^{-1}$, are associated with optical phonons, two transverse acoustic (2TA) phonons, and two transverse optical (2TO) phonons of w-Si (Mohiddon \& Kirshna, 2011) respectively. The asymmetric nature of the peak at $504 \mathrm{~cm}^{-1} \mathrm{can}$ 
be attributed to the presence of small amounts of $a$-Si, which has its broad peak at $480 \mathrm{~cm}^{-1}$. In general, when Si crystallizes in cubic diamond structure the Raman peak occurs at 520 $\mathrm{cm}^{-1}$. The broad peaks around $283 \mathrm{~cm}^{-1}$ in our observation is may belong to $\mathrm{NiSi}, \mathrm{NiSi}_{2}$ or to wurtzite TA mode. However, this observation implies that, at $550{ }^{\circ} \mathrm{C}$ nickel silicides are present in the samples. Tan et al. (Tan et al., 1981) reported a stress-induced metastable form of hexagonal silicon, which has the wurtzite structure with the c/a ratio close to 1.63 , the interplanar distances and angular relationships obtained from our experiment were compared with those of silicon which has the wurtzite structure. However, for silicon with the wurtzite structure, no exact coincidence was obtained. Kim et al. reported a similar observation and suggested a hexagonal phase of $\operatorname{Si}$ with $a=0.382 \mathrm{~nm}, c=1.024 \mathrm{~nm}$ and $c / a$ ratio of 2.68 (Kim \& Lee, 1996). Parson and Hoelke suggested similar hexagonal structure for Ge with $c / a$ ratio of 2.17 (Parsons \& Hoelke, 1983). Zhang et al. (Zhang et al., 1994) have reported wurzite silicon by laser ablation, and they observed Raman peaks at 516 and 518 $\mathrm{cm}^{-1}$ due to the hexagonal silicon. Kumar et al. observed $w$-Si in chromium induced $\mathrm{Si}$ crystallization evidenced by a peak at $495 \mathrm{~cm}^{-1}$ (Kumar \& Krishna, 2008). Kailer et al. (Kailer et al., 1997) performed indentation Raman investigations and reported that, shear deformation leads to $w$-Si phase formation. They also stated that high pressure phases leads to the formation of $w$-Si at moderate temperatures and to the reversal to the original diamond structure at higher temperatures.

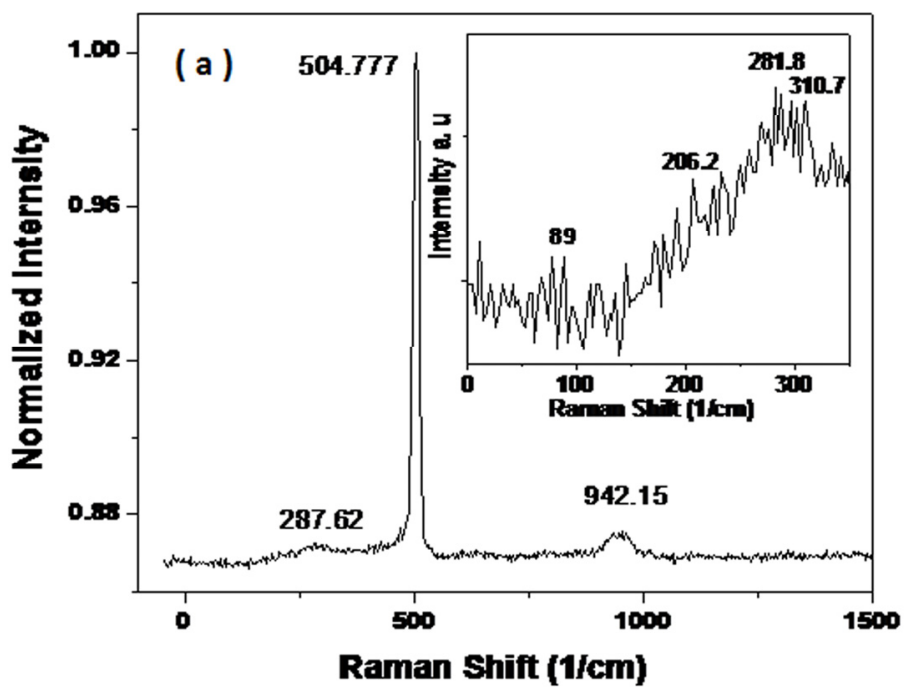

Fig. 9. Raman spectra of BSG/Ni/Si stack annealed at $550^{\circ} \mathrm{C}$ for $1 \mathrm{hr}$ (Mohiddon et al., 2011).

\subsection{Chromium induced crystallization}

The search for new metal in the MIC process to reach the best device needs is still continuing. Chromium is another member of the silicide forming group. Chromium induced MIC has attracted our attention due to its ability to crystallize the $a$-Si into wurtzite phase (Kumar et al., 2008). Our recent work on $\mathrm{Cr}$ induced MIC has revealed that $\mathrm{Cr}$ deposited at 
ambient substrate temperature, remains in metallic form up to an annealing temperature of $500{ }^{\circ} \mathrm{C}$ (Mohiddon et al.,2012). As an extension of this work we deposited $\mathrm{Cr} / \mathrm{Si}$ stacks at higher substrate temperature. The details of the experiment are as follows. A $\mathrm{Cr}(200 \mathrm{~nm}) / \mathrm{Si}(400 \mathrm{~nm})$ stack was deposited over a fused silica substrate at $400{ }^{\circ} \mathrm{C}$ substrate temperature and a similar stack of $\mathrm{Cr}(50 \mathrm{~nm}) / \mathrm{Si}(400 \mathrm{~nm})$ was deposited at ambient substrate temperature by electron beam evaporation. We have carried out a detailed EXAFS analysis on these set of samples (Mohiddon et al., 2012) and concluded that, in case of film deposited at ambient substrate temperature, major part of $\mathrm{Cr}$ is in metallic form apart from being oxidized. In the case of the stack deposited at $400{ }^{\circ} \mathrm{C}$, the entire $\mathrm{Cr}$ is turned into either $\mathrm{Cr}_{2} \mathrm{O}_{3}$ or $\mathrm{CrSi}_{2}$. After the EXAFS measurements were completed, these samples were heat treated at different temperatures. Samples were annealed at 600,650 and $700{ }^{\circ} \mathrm{C}$ for $1 \mathrm{hr}$. in excess Nitrogen flux. At each heat treatment, the samples were cooled to room temperature and then the Raman spectra were collected at three to four different position of the each sample. The details of the Raman measurements are discussed in the section 4.3 of the chapter.

Figure 10(a) and 10(b) compares the Raman spectra of the FS/Cr(200nm)/Si(400nm) stack deposited at $400{ }^{\circ} \mathrm{C}$ substrate temperature and $\mathrm{FS} / \mathrm{Cr}(50 \mathrm{~nm}) / \mathrm{Si}(400 \mathrm{~nm})$ stack deposited ambient substrate temperature then annealed at different temperature respectively. Fig. 10(a) shows that the as deposited stack contains a broad diffuse peak around $480 \mathrm{~cm}^{-1}$ that can be assigned to the a-Si phase. After the heat treatment at $600{ }^{\circ} \mathrm{C}$, a sharp peak, around $520 \mathrm{~cm}^{-1}$, appears that can be assigned to c-Si. The intensity of the c-Si peak increases with annealing temperature up to $650^{\circ} \mathrm{C}$. No such change in the Raman spectra is observed in the Fig. 10 (b). By combining the EXAFS and Raman results we conclude that the FCS stack deposited at $400^{\circ} \mathrm{C}$ possesses $\mathrm{CrSi}_{2}$ in the as deposited condition. When this stack is further heat treated the $\mathrm{CrSi}_{2}$ acts as a seed for the Si crystallization. In the FCS stack deposited at minimum substrate temperature, no $\mathrm{CrSi}_{2}$ is observed from the EXAFS analysis. Thus even after heat treatment up to $700 \mathrm{C}$, no Si crystallization is observed.
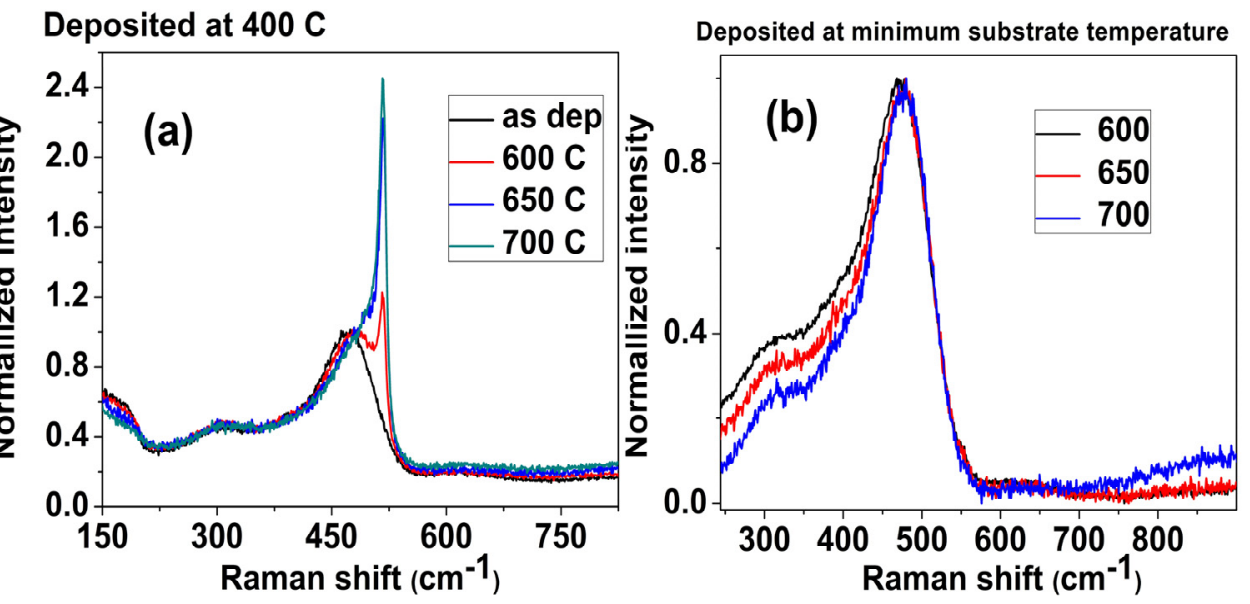

Fig. 10. Raman spectra of (a) FS/Cr(200nm)/Si(400nm) stack deposited at 400 C; (b) FS/Cr(50nm)/Si(400nm) stack deposited at minimum substrate temperature 


\section{Conclusions}

An overview of the metal induced crystallization of amorphous Silicon films has been presented. The possible mechanisms of crystallization have been discussed. Two metals Sn and $\mathrm{Cr}$, which have not been used frequently for MIC, have been shown to be as attractive as $\mathrm{Ni}$ for metal induced crystallization of a-Si. Our results clearly show that these are very useful materials for the microelectronics industry. The crystallization occurs at temperatures ranging from 200 to $600^{\circ} \mathrm{C}$, which is much lower than the normal crystallization temperature of $\mathrm{Si}$ $\left(1100^{\circ} \mathrm{C}\right)$. The stabilization of the wurtzite form of $\mathrm{Si}$ has also been demonstrated.

\section{Acknowledgements}

The authors acknowledge discussions with Prof. F. Rocca and Prof. G. Dalba of University of Trento and funding for this work through the DST-ITPAR program. Facilities provided by the CAS programme of the School of Physics and DST funded Centre for Nanotechnology at the University of Hyderabad are also acknowledged.

\section{References}

Choi, J.H., Cheon, J.H., Kim, S.K., \& Jang, J. (2005). Giant-grain silicon (GGS) and its application to stable thin film transistor. Displays 26, 3, (June 2005), pp. (137-142), ISSN 0141-9382

Bandet, J., Despax, B., \& Caumont, M. (2002). Vibrational and electronic properties of stabilized wurtzite like silicon. Journal of Physics D: Applied Physics, 35, 3, (January 2002), pp. (234-239), ISSN 1361-6463

Ferri, F.A., Zanatta, A.R., \& Chambouleyron, I. (2006). Metal-induced nanocrystalline structures in Ni-containing amorphous silicon thin films. J. Appl. Phys., 100, 9, (November 2006), pp. (094311-094317), ISSN 0021-8979

Grisenti, R., Dalba, G., Fornasini, P., Rocca, F., Kumar, K.U.M., \& Krishna, M.G. (2008). XAFS study on Ni surroundings in metal induced crystallization of thin film amorphous silicon. Solid State Comm., 147, 9-10, (September 2008), pp. (401-404) ISSN 0038-1098

Hayzelden, C., \& Batstone, J.L. (1993). Silicide formation and silicide-mediated crystallization of nickel-implanted amorphous silicon thin films. J. Appl. Phys., 73, 12, (February 1993), pp. (8279-8289), ISSN 0021-8979

Hiraki, A. (1980). A model on the mechanism of room temperature interfacial intermixing reaction in various metal-semiconductor couples: what triggers the reaction?. J. Electrochem. Soc. 127, 12, (December 1980), pp. (2662-2665), ISSN 1945-7111

Hong, I., Hsu, T.C., Yen, S.C., Lin, F.S., Huang, M.L., \& Chen, C.H. (2006). Proc. 8th Int. Conf. X-ray Microscopy, IPAP Conf. Series 7 (2006) 270.

Hwang, J.D., \& Lin, J.W. (2005). Nanostructural silicon films prepared by metal induced growth using RTCVD system. J. Electrochem. Soc., 152, 1, (Novermber 2005), pp. (G35-G39), ISSN 1945-7111

Jeon, M., Jeong, C., \& Kamisako, K. (2010). Tin induced crystallization of hydrogenated amoprphous silico, K., Kowk, H.S., \& Wang, M. (1999), The effects of extended heat treatment on $\mathrm{Ni}$ induced lateral crystallization of amorphous silicon thin films. IEEE Trans. Electron Devices, 46, 1, (January 1999), pp. (78-82), ISSN 0018-9383 
Jin, Z., Bhat, G.A., Yeung, M., Kwok, H.S., \& Wong, M. (1998). Nickel induced crystallization of amorphous silicon thin film. J. Appl. Phys. 84, 1, (April 1998), pp. (194-200) ISSN 0021-8979.

Kailer, A., Gogotsi, Y.G., \& Nickel, K.G. (1997). Phase transformation of silicon caused by contact loading. J. Appl. Phys., 81, 7, (January 1997), pp. (3057-3063), ISSN 0021-8979

Kim, J.H., \& Lee, J.Y. (1996). Hexagonal silicon formation by pusled laser beam annealing. Materials Letters 27, 6, (August 1996), pp. (275-279), ISSN 0167-577X

Kozlowski, F., Petrova-Koch, V., Kux, A., Stadler, W., Fleischmann, A., \& Sigmund, H. $(1991)$. Structural instability of Si-nanocrystals in a $\left(\mathrm{SiH}_{2}\right)_{\mathrm{n}}$. J. Non-Cryst. Solids, 137138, 1, (January 1991), pp. (91-94), ISSN 0022-3093

Kumar, K.U.M., Brahma, R., Krishna, M.G., Bhatnagar, A.K., \& Dalba, G. (2007). An optical study of Ni induced crystallization of a-Si thin films. J. Phys. Condens. Matter 19, 49, (December 2007), pp. (496208-1-11), ISSN 1361-648X

Kumar, K.U.M., \& Krishna, M.G., (2008). Chromium-induced nanocrystallization of a-Si thin films into the wurtzite structure. J. Nanomater. 2008, (February 2008), pp. (736534-1-6)

Lee, C.J., Lee, J.B., Chung, Y.C., \& Choi D.K. (2000). Lateral crystallization of amorphous silicon films. Jpn. J. Appl. Phys. 39, (2000), pp. (6191-6195), ISSN 1347-4065

Leonard, R.T., \& Koch, C.C. (1992). Nanoscale composites of Si/Sn and Ge/Sn synthesized by mechanical attrition. Nanostructured Materials, 1, 6, (December 1992), pp. (471478), ISSN: 0965-9773

Mahan, A.H., Ahrenkiel, S.P., Schropp, R.E.I., Li, H., \& Ginley, D.S. (2008). A comparison of grain nucleation and grain growth during crystallization of HWCVD and PECVD a-Si:H films. Thin Solid Films, 516, 5, (January 2008), pp. (529-532), ISSN 0040-6090

McCaldin, J. O., \& Sankur, H. (1971). Diffusivity and solubility of Si in the Al metallization of integrated circuits. Appl. Phys. Lett., 19, 12, (July 1971), pp. (524-527), ISSN 0003-6951

Mohiddon, M.A., \& Krishna, M.G. (2011). Nanocrystalline wurtzite Si-nickel silicide composite thin films with large band gap and high resistivity. J Mater. Sci., 46, 8, (April 2011), pp. (2672-2677), ISSN 1573-4803

Mohiddon, M.A., \& Krishna, M.G. (2012) Growth and optical properties of Sn-Si nanocomposite thin films J. Material Science, DOI: 10.1007/s10853-012-6647-0

Mohiddon, M.A., \& Yadav, K. L. (2008). Effect of $90^{\circ}$ domain on ferroelectric properties of alkali modified SBN. J. Phys. D: Appl. Phys., 41, 22, (October 2008), pp. (225406-1-7), ISSN 1361-6463

Mohiddon, M.A., Naidu, K.L., Dalba, G., Rocca, F., \& Krishna, M.G. (2012) unpublished

Mohiddon, M.A., Naidu, K.L., Dalba, G., Rocca, F., \& Krishna, M.G. (2012) Cr induced nanocrystallization of a-Si thin films: its mechanism Physica Status Solidi C, 9 (April 2012), pp. (1493-1495 )1493-1495

Mohiddon, M.A., Naidu, K.L., Dalba, G., Rocca, F., \& Krishna, M.G. (2011) Growth, optical, and electrical properties of silicon films produced by the metal-induced crystallization process, J Nanopart Res 13 (June 2011), pp. (5999-6004).

Mohiddon, M.A., Krishna, M.G., Dalba, G. \& Rocca, F. (2012) Transmission electron microscopy study of Ni-Si nanocomposite films Mate. Sci. Eng. B, DOI: 10.1016/j.mseb.2012.05.018

Murray, J. L., \& McAlister, A.J. (1984). Al-Si. Bull. Alloy Phase Diagram, 5,1 (January 1984), pp. (74-84) ISSN 0197-0216. 
Nast, O., \& Wenham, S.R. (2000). Elucidation of the layer exchange mechanism in the formation of polycrystalline silicon by aluminum induced crystallization. J. Appl. Physics, 88, (January 2000), pp. (124-131), ISSN 0021-8979

Oliver, N., \& Hartmann, A. J. (2000). Influence of interface and Al structure on layer exchange during aluminum induced crystallization of amorphous silicon. J. Appl. Phys. 88 (April 2000), pp. (716-724) ISSN 0021-8979

Park, S.H., Jun, S.I., Song, K.S., Kim, C.K., \& Choi, D.K. (1999). Field aided lateral crystallization of amorphous silicon thin film. Jpn. J. Appl. Phys., 38, 2, (January 1999), pp. (L108-L109), ISSN 1347-4065

Park, K.C., Song, I.H., Jeon, J.H., \& Han, M.K. (2001). Excimer laser annealing effect on Nickel-induced crystallized polycrystalline silicon film. J. Electrochem. Soc., 148, 10, (August 2001), pp. (G563-G565), ISSN 1945-7111

Parr, A.A., Gill, K., Gardiner, D., Holyland, J., Sands, D., Brunson, K., \& Carline, R. (2002). A comparison of laser- and furnace- annealed poly-silicon structure. Semicond. Sci. Technol. 17, 1, (January 2002), pp. (47-54), ISSN 1361-6641

Parsons, J.R., \& Hoelke, C.W. (1983). Crystallography Of hexagonal germanium. Nature, 30, 5901, (1983), pp. (591-592), ISSN 1476-4687

Russell, S. W., Jian, Li., \& Mayer, J. W. (1991). In situ observation of fractal growth during aSi crystallization in a $\mathrm{Cu}_{3} \mathrm{Si}$ matrix. J. Appl. Phys., 70, 9, (August 1991), pp. (51535155), ISSN 0021-8979

Schropp, R.E.I., \& Zeman, M. (1998). Amorphous and Microcrystalline Silicon Solar Cells:Modeling, Materials and Device Technology, Kluwer Academic Publishers, ISBN 978-0-7923-8317-8, Boston.

Spinella, C., Lombardo, S., \& Priolo, F. (1998). Crystal grain nucleation in amorphous silicon. J. Appl. Phys., 84, 10, (July 1998), pp. (5383-5415), ISSN 0021-8979

Sui, Z., Leong, P.P., Herman, I.P., Higashi, G.S., \& Temkin, H. (1992). Raman analysis of light emitting porous silicon. Appl. Phys. Lett., 60, 17, (February 1992), pp. (20862088), ISSN 0003-6951

Tan, T.Y., Foll, H., Hu, S.M. (1981). On the diamond-cubic to hexagonal phase transformation in silicon. Philos. Mag. A, 44, 1, (July 1981), pp. (127-140), ISSN 1478-6443

Wang, M., \& Wong, M. (2001). Characterization of an individual grain boundary in metalinduced laterally crystallized polycrystalline silicon thin-film device. IEEE Trans. Electron Devices, 48, 8, (August 2001), pp. (1655-1660), ISSN 0018-9383

$\mathrm{Wu}$, B.R. (2000). First- principles study on the high-pressure behavior of the zone-center modes of lonsdaleite silicon. Phys. Rev. B, 61, 1, (January 2000), pp. (5-8), ISSN 1550-235X

Yoon, S. Y., Park, S. J., Kim, K. H., \& Jang, J. (2001). Metal induced crystallization of amorphous silicon. Thin Solid Films, 383, 1-2, (February 2001), pp. (34-38), ISSN 0040-6090

Zener, C. (1949). Theory of growth of spherical precipitates from solid solution. J. Appl. Phys., 20, 10, (March 1949), pp. (950-953), ISSN 0021-8979

Zhang, Y., Iqbal, Z., Vijayalakshmi, S., \& Grebel, H. (1999). Stable hexagonal wurtzite silicon phase by laser ablation. Appl. Phys. Lett., 75, 18, (September 1999), pp. (2758-2760), ISSN 0003-6951

Zhang, S.L., Wang, X., Ho, K., Li, J.J., Diao, P., \& Cai, S. (1994). Raman spectra in a broad frequency region of p- type porous silicon. J. Appl. Phys. 76, 5, (May 1994), pp. (3016-3019), ISSN 0021-8979 
(C) 2012 The Author(s). Licensee IntechOpen. This is an open access article distributed under the terms of the Creative Commons Attribution 3.0 License, which permits unrestricted use, distribution, and reproduction in any medium, provided the original work is properly cited. 